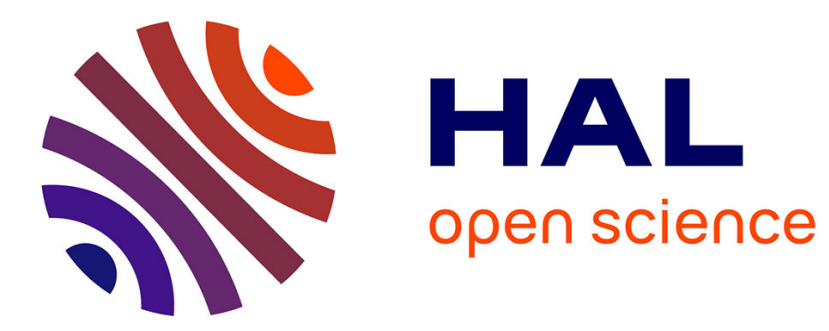

\title{
Aromatic Guanylhydrazones for the Control of Heme-Induced Antibody Polyreactivity
}

Nina Božinović, Vladimir Ajdačić, Jelena Lazic, Maxime Lecerf, Victoria Daventure, Jasmina Nikodinovic-Runic, Igor M Opsenica, Jordan Dimitrov

\section{- To cite this version:}

Nina Božinović, Vladimir Ajdačić, Jelena Lazic, Maxime Lecerf, Victoria Daventure, et al.. Aromatic Guanylhydrazones for the Control of Heme-Induced Antibody Polyreactivity. ACS Omega, 2019, 4 (24), pp.20450-20458. 10.1021/acsomega.9b01548 . hal-02405089

\section{HAL Id: hal-02405089 \\ https://hal.sorbonne-universite.fr/hal-02405089}

Submitted on 11 Dec 2019

HAL is a multi-disciplinary open access archive for the deposit and dissemination of scientific research documents, whether they are published or not. The documents may come from teaching and research institutions in France or abroad, or from public or private research centers.
L'archive ouverte pluridisciplinaire HAL, est destinée au dépôt et à la diffusion de documents scientifiques de niveau recherche, publiés ou non, émanant des établissements d'enseignement et de recherche français ou étrangers, des laboratoires publics ou privés. 


\title{
Aromatic Guanylhydrazones for the Control of Heme-Induced Antibody Polyreactivity
}

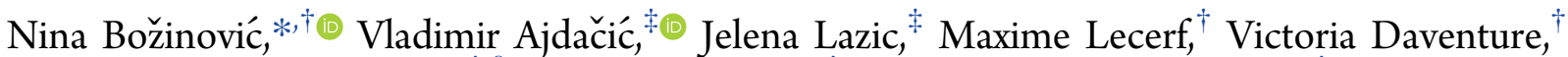 \\ Jasmina Nikodinovic-Runic, ${ }^{\ddagger}, \S$ Igor M. Opsenica, ${ }^{\ddagger}$ and Jordan D. Dimitrov ${ }^{*}{ }^{\dagger}$ \\ ${ }^{\dagger}$ Centre de Recherche des Cordeliers, INSERM, Sorbonne Université, USPC, Université Paris Descartes, Université Paris Diderot, \\ F-75006 Paris, France \\ ${ }^{*}$ University of Belgrade-Faculty of Chemistry, Studentski trg 16, P.O. Box 51, 11158 Belgrade, Serbia \\ ${ }^{\S}$ Institute of Molecular Genetics and Genetic Engineering, University of Belgrade, Vojvode Stepe 444a, 11000 Belgrade, Serbia
}

\section{Supporting Information}

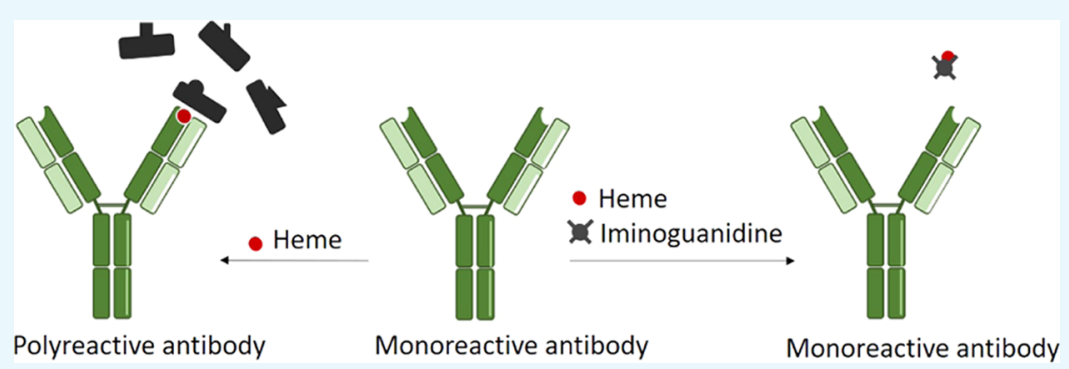

ABSTRACT: In a healthy immune repertoire, there exists a fraction of polyreactive antibodies that can bind to a variety of unrelated self- and foreign antigens. Apart from naturally polyreactive antibodies, in every healthy individual, there is a fraction of antibody that can gain polyreactivity upon exposure to porphyrin cofactor heme. Molecular mechanisms and biological significance of the appearance of cryptic polyreactivity are not well understood. It is believed that heme acts as an interfacial cofactor between the antibody and the newly recognized antigens. To further test this claim and gain insight into the types of interactions involved in heme binding, we herein investigated the influence of a group of aromatic guanylhydrazone molecules on the heme-induced antibody polyreactivity. From the analysis of SAR and the results of UV-vis absorbance spectroscopy, it was concluded that the most probable mechanism by which the studied molecules inhibit heme-mediated polyreactivity of the antibody is the direct binding to heme, thus preventing heme from binding to antibody and/or antigen. The inhibitory capacity of the most potent compounds was substantially higher than that of chloroquine, a well-known heme binder. Some of the guanylhydrazone molecules were able to induce polyreactivity of the studied antibody themselves, possibly by a mechanism similar to heme. Results described here point to the conclusion that heme indeed must bind to an antibody to induce its polyreactivity, and that both $\pi$-stacking interactions and iron coordination contribute to the binding affinity, while certain structures, such as guanylhydrazones, can interfere with these processes.

\section{INTRODUCTION}

Specificity and diversity of adaptive immune responses are critical features for the proper functioning of the immune system. These properties of the immune response originate from antigenic receptors on $\mathrm{T}$ and $\mathrm{B}$ cells and circulating immunoglobulins. It is estimated that the human immune system can generate $10^{26}$ possible B-cell receptor sequences from $\mathrm{V}, \mathrm{D}$, and $\mathrm{J}$ region recombination and somatic hypermutations, providing enormous binding diversity. ${ }^{1,2}$ In the early days of immunology research, it was believed that each antibody is highly specific for a single antigen. It is now a well-established fact that the significant fraction of B-cell receptors and antibodies in a healthy immune repertoire is capable of binding to numerous structurally unrelated self- or foreign antigens. $^{3-7}$ This phenomenon often referred to as antibody polyreactivity, contributes to the diversification of immune specificities and facilitates the recognition of pathogens in the early stages of infection.

Apart from polyreactivity occurring naturally, there exist cryptic polyreactivity that can be induced post-translationally. Exposure to physiologically relevant redox-active substances, such as iron ions, reactive oxygen species, and heme causes the appearance of polyreactivity in a fraction of human immunoglobulins. $^{8-12}$ There is evidence suggesting that heme (iron protoporphyrin IX) induces antibody polyreactivity by direct binding to the variable region of immunoglobulin molecules. The binding site of heme most probably overlaps with the antigen-binding site and heme is engaged in binding to newly recognized antigens. ${ }^{13,14}$ Heme molecules contain

Received: May 27, 2019

Accepted: August 6, 2019

Published: November 22, 2019 


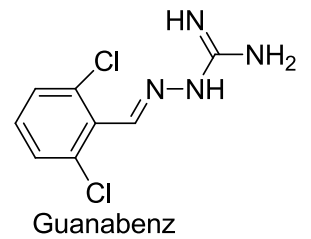<smiles>[R]c1ccc(-c2ccc(/C=N/NC(=N)N)[X]2Cl)cc1</smiles>

1. $X=O, R=H$

2. $X=O, R=\mathrm{CH}_{3}$

3. $\mathrm{X}=\mathrm{O}, \mathrm{R}=\mathrm{OCH}_{3}$

4. $\mathrm{X}=\mathrm{S}, \mathrm{R}=\mathrm{CH}_{3}$

5. $\mathrm{X}=\mathrm{S}, \mathrm{R}=\mathrm{OCH}_{3}$

6. $X=S, R=C N$

7. $\mathrm{X}=\mathrm{S}, \mathrm{R}=\mathrm{Br}$<smiles>N=C(N)N/N=C/c1ccc(-c2ccncc2)s1</smiles>

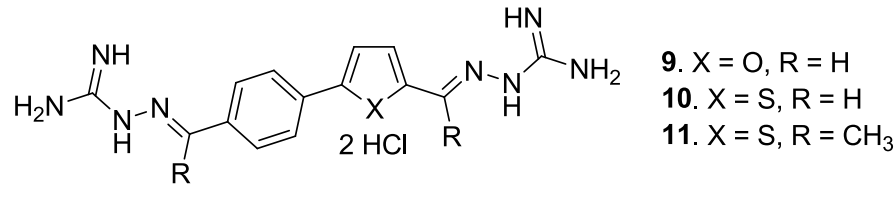<smiles>[Y20][Y](=C)=N</smiles>

Figure 1. Structure of aromatic guanylhydrazones.

aromatic pyrrole rings and other hydrophobic groups, as well as polar, anionic carboxylate groups and an iron ion capable of coordinative interactions. Such structure provides numerous possibilities for noncovalent interactions with both immunoglobulins and possible new antigens. ${ }^{15}$ However, the molecular mechanism of the induced antibody polyreactivity is not well understood. Additionally, there is no strategy so far for the control of this phenomenon under physiopathological conditions where the massive release of intracellular heme occurs such as in hemolytic diseases. ${ }^{9}$ Thus, compounds that have the capacity to inhibit the effect of heme on antibodies may demonstrate therapeutic activity for amelioration of the negative proinflammatory effects of extracellular heme in disorders such as malaria, sickle cell disease, and autoimmune hemolytic anemia.

To gain an insight into the type of interactions involved, we examined the effect of a series of heterocyclic guanylhydrazone (iminoguanidine) molecules on the ability of heme to induce polyreactivity of a prototypic human monoclonal IgG1. This antibody (Ab21) was previously identified to gain the capacity to bind with high affinity to structurally different protein antigens upon heme exposure. ${ }^{14,16,17}$ The guanylhydrazone series of molecules investigated here were chosen based on their expected ability to bind heme by noncovalent interactions. The studied molecules differed in the number of aromatic rings and positively charged guanylhydrazone groups, thus providing different possibilities for coordinative, ionic and $\pi$-stacking interactions with heme and heme-binding site on the immunoglobulin. We hypothesized that with the gradual increase in the number of structural elements capable of interacting with heme, the molecules will exhibit a stronger inhibiting effect on the heme-induced antibody polyreactivity. Over the past few years, various compounds containing the guanylhydrazone (iminoguanidine) moiety have attracted much attention for their versatile biological activities. These compounds were extensively studied for their antiviral, ${ }^{18,19}$ antiparasitic, $^{20}$ antibacterial, $^{21-23}$ and antifungal activities. ${ }^{24-26}$ The ability of the compounds to inhibit or induce antibody polyreactivity was investigated using standard immunoassays and their interactions with heme were followed by UV-vis spectroscopic measurements. We compared the influence of our compounds on the heme-induced polyreactivity with that of the antimalarial drug chloroquine, which is known to bind to heme and perturb its interactions. Chloroquine inhibits the crystallization of toxic ferriprotoporphyrin IX to nontoxic crystalline hemozoin by binding to monomeric or dimeric forms of free heme, depending on the chemical environment. ${ }^{27}$

\section{RESULTS AND DISCUSSION}

To study the molecular interactions involved in antibodyheme binding, we treated $\mathrm{Ab} 21$ with a series of guanylhydrazones prior to heme exposure and followed the changes in the $\mathrm{Ab}$ binding potential to protein antigens. Aromatic guanylhydrazones (Figure 1) were chosen based on their structures that can provide the possibility for different types of interactions with heme. They possess positively charged guanylhydrazone groups that can interact with carboxylates and aromatic rings (benzene, thiophene, furan, or thiazole) that can form noncovalent interactions with pyrrole rings. Furthermore, a number of heteroatoms in their structure can potentially coordinate with an iron ion in the center of the protoporphyrin IX macrocyclic core. The studied molecules differed in the number and type of aromatic rings and positively charged guanylhydrazone groups. The simplest studied molecule is guanabenz, an approved drug that is used as an antihypertensive agent. ${ }^{28}$ It is composed of only one substituted benzene ring and one guanylhydrazone group (Figure 1). Other synthetic iminoguanidines used in this study were previously determined to exhibit significant antifungal activity. ${ }^{24-26}$ They were divided into three groups based on the 
structure complexity. The first group of compounds (compounds 1-8) contained one positively charged iminoguanidine group and two hydrophobic aromatic rings. Molecules in the second group (9-11) were composed of two positively charged iminoguanidine groups and two hydrophobic aromatic rings. The third group (12 and 13) had one additional benzene ring compared to the second group.

Acquired Polyreactivity of Ab21. To confirm hemesensitivity of $A b 21$, the binding potential to protein antigens of native and heme-treated antibody was compared. The selected antibody acquires a strong binding potential for both human and bacterial antigens after heme treatment (Figure 2). After
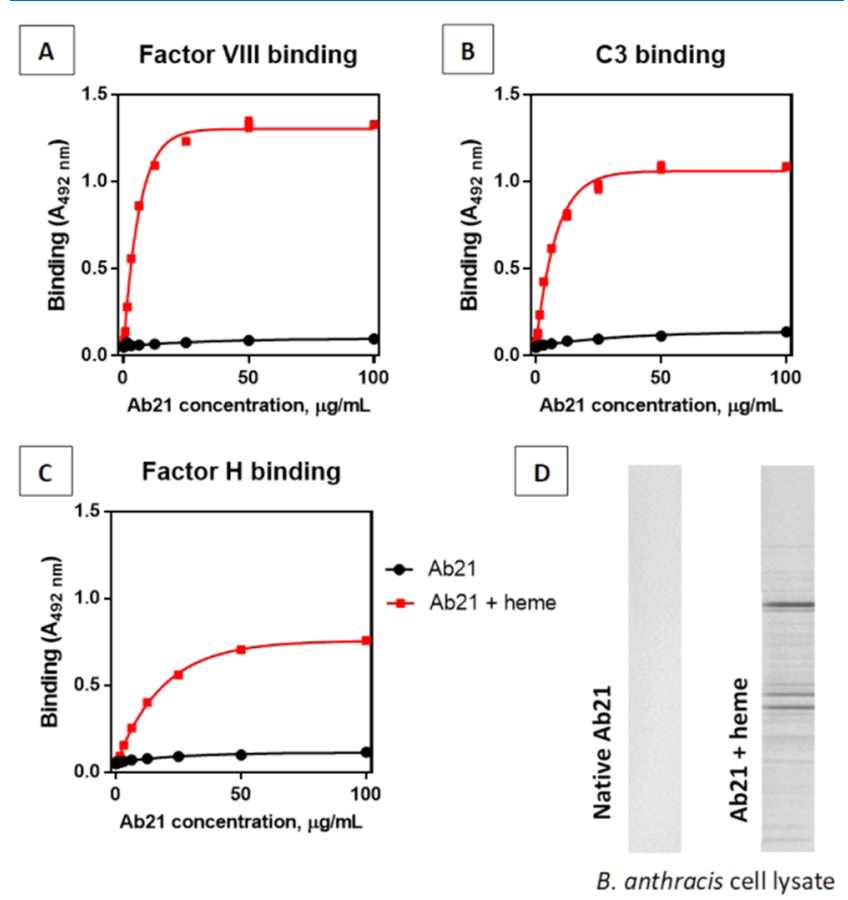

Figure 2. Heme-induced Ab21 polyreactivity by immunosorbent assay $(\mathrm{A}-\mathrm{C})$ and immunoblot (D).

exposure to two times molar excess of heme, there was substantial binding of Ab21 to human factor VIII, human C3, and human factor $\mathrm{H}$, as seen in ELISA experiments (Figure $2 \mathrm{~A}-\mathrm{C})$. Immunoblot analysis of the interaction of native and heme-exposed Ab21 with immobilized Bacillus anthracis proteins is in agreement with the conclusion that initially nonreactive $\mathrm{Ab} 21$ acquires the ability to bind to diverse antigens (Figure 2D).

Inhibition of Heme-Induced Antibody Polyreactivity. We evaluated the efficacy of guanylhydrazones to inhibit hemeinduced polyreactivity of $\mathrm{Ab} 21$. The antibody was treated with a 30-fold molar excess of tested compounds, followed by the addition of a 15-fold molar excess of heme. Binding of native and heme-treated antibody to three human antigens was examined by ELISA. We hypothesized that the increase in the complexity will result in an increase of the inhibiting potential of a given molecule since there is a higher possibility of it to interact with heme and hence prevent heme from binding to the IgG. The experiment demonstrated that all tested guanylhydrazones, except for guanabenz, were able to reduce heme-induced antibody polyreactivity. Most of the compounds were considerably more efficient inhibitors than the wellknown heme-binding compound, chloroquine. However, contrary to our prediction, there is a trend of decrease of inhibitory potential with an increase of the molecular complexity (Figure 3). This may be explained by the lower possibility for the molecules with higher complexity to adopt a planar conformation that is necessary for the aromatic moieties to be employed in interactions with the porphyrin ring. Under experimental conditions applied here, compounds 1-5 were able to completely inhibit acquired polyreactivity of Ab21. To determine more precisely and compare inhibiting potentials of the two most potent compounds 3 and 4, Ab21 was treated with decreasing concentrations of $\mathbf{3}$ or $\mathbf{4}$ in the presence of a constant concentration of hemin. The binding of treated and non-treated antibody was followed by ELISA and western blot (Figure 4A,C). In both experiments, compound 3 was revealed to be more efficient, given that a lower concentration was required to completely neutralize the activating potential of heme (approximately equimolar concentration to heme). The estimated half-maximal inhibitory concentrations $\left(\mathrm{IC}_{50}\right)$ of compounds 3 and 4 were 3.0 and $5.5 \mu \mathrm{M}$, respectively. An important point can be made for compound 11 that has methyl substituents on the carbon of the iminoguanidine group, compared to compound $\mathbf{1 0}$ that has hydrogen in the same position. Steric hindrance adjacent to nitrogen atoms decreases the inhibiting potential of the compound, indicating that these nitrogen atoms play an important role in the mechanism of the inhibition of the induced polyreactivity, possibly by coordinating iron ion of heme. This observation points to the conclusion that guanylhydrazones interact directly with heme and block its interaction with antibody and/or antigen. Our conclusion is further supported by the fact that compounds $\mathbf{3}$ and $\mathbf{4}$ were also able to completely inhibit heme-induced polyreactivity of pooled immunoglobulin $\mathrm{G}$, which is obtained from plasma of a large number of healthy donors (IVIg), as can be seen from the ELISA experiment (Figure 4B). Although we cannot completely exclude the possibility that the compounds interact with immunoglobulins, the fact that they inhibit heme-induced polyreactivity of many different immunoglobulins in the mixture is in accordance with the conclusion that the inhibitory effect of the compounds is the consequence of their interactions with heme, rather than with somatically maturated Ab21.

Spectroscopic Investigation of Interactions of Heme with Compounds 1-13. The interaction of heme with different molecules results in the changes in the Soret region of the UV-vis absorbance spectrum of oxidized heme. ${ }^{29} \mathrm{We}$ hypothesized that guanylhydrazones prevent the binding of heme to antibodies by direct interaction through $\pi$-stacking interactions and coordination of the iron ion. To test this assumption, we estimated the influence of the tested compounds on the UV-vis absorbance spectrum of hemin. The spectrum of $20 \mu \mathrm{M}$ hemin in PBS displayed the characteristic maximum in the Soret region, at $382 \mathrm{~nm}$. The addition of five times excess of guanylhydrazones resulted in a red shift of the absorbance maximum and a decrease of the absorbance intensity. Differential spectra were obtained by subtraction of the individual spectra of hemin and the compound from the spectra of their mixture (Figure 5, left). Next, the percentage of the inhibition of heme-induced antibody binding to factor VIII was plotted against the absolute value of $\Delta A$ at the absorbance minimum of each differential spectrum (Figure 5, right). A general trend can be observed of the increase of inhibiting potential with the increase of the absorbance intensity change $\left(R^{2}=0.43, p=\right.$ 

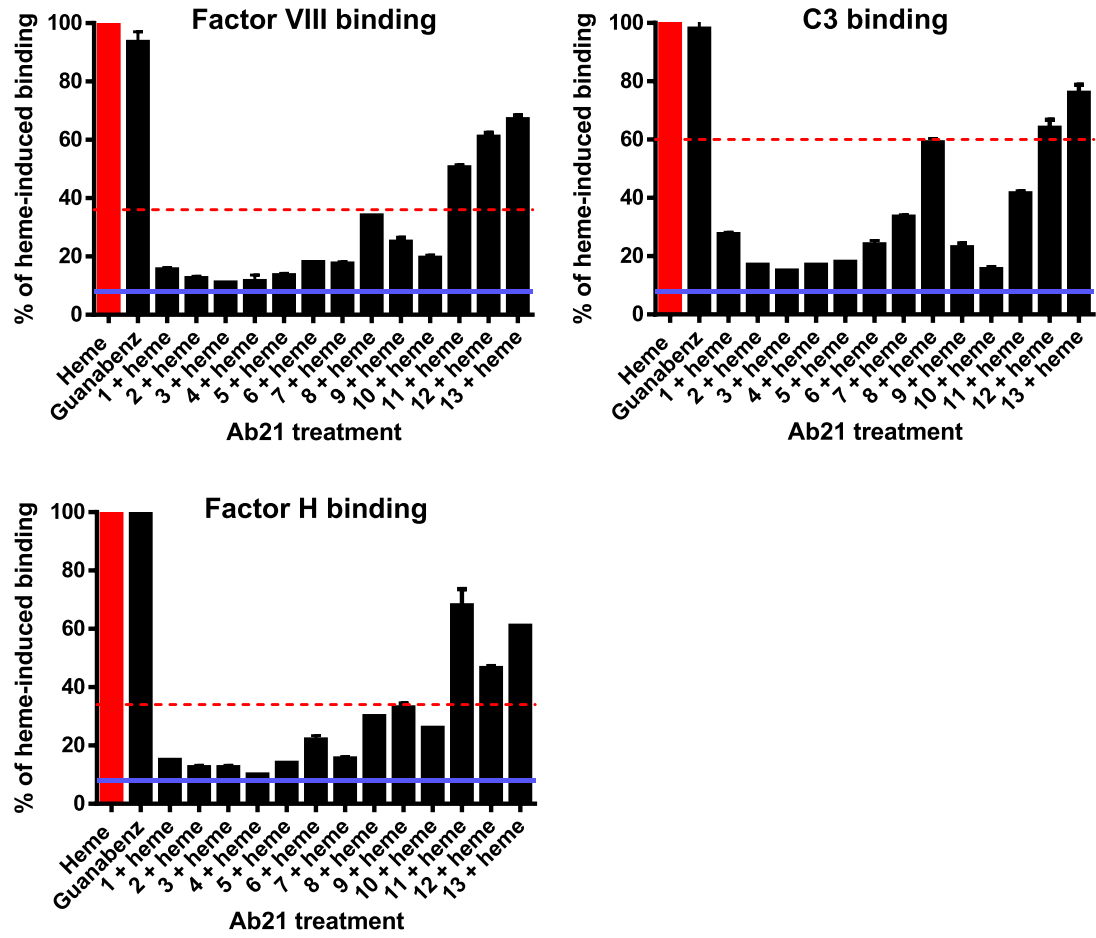

Figure 3. Results of the study of inhibition of heme-induced Ab21 polyreactivity by immunosorbent assay. Binding to particular antigen was expressed as a percentage of the binding of the heme-exposed Ab21. Binding of native Ab21 is represented by the blue line and binding of Ab21 exposed to chloroquine and heme is represented by the red line.

A Factor VIII binding of Ab21

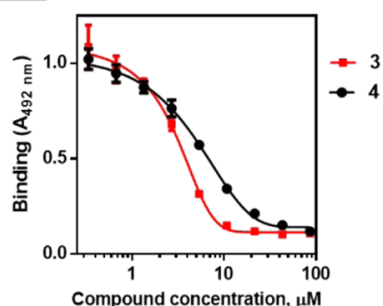

B Factor VIII binding of IVIg

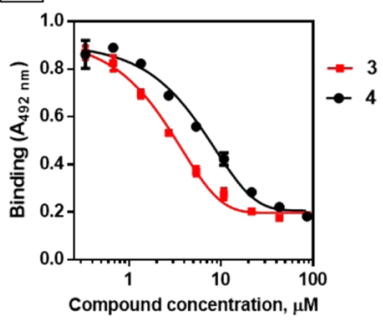

Compound concentration, $\mu \mathrm{M}$

Figure 4. Inhibitory potential of compounds 3 and 4 determined by immunosorbent assay (left) and immunoblot (right). Ab21 (A) or IVIg (B) was treated with an excess of hemin and with increasing concentrations of guanylhydrazones.

0.016). The obtained data suggest that the direct interaction of guanylhydrazones with heme is to a significant extent responsible for the diminished capacity of heme to induce antigen-binding polyreactivity of the antibody.

Spectroscopic Investigation of the Influence of Compound $\mathbf{3}$ on Antibody-Heme Interactions. It was previously demonstrated that the binding of heme to Ab21 can be followed by absorbance spectroscopy. ${ }^{14}$ Here, we confirmed that the exposure of $2 \mu \mathrm{M} \mathrm{Ab} 21$ to $16 \mu \mathrm{M}$ hemin results in an increase in the absorbance intensity of hemin and a substantial red shift in the high energy region (black line in Figure 6, left), which is consistent with binding of heme and coordination of its central iron ion to the antibody molecule. To test the influence of compound 3 on antibody-heme binding, we followed the changes in the UV-vis absorbance spectrum of the $\mathrm{Ab} 21$ and the hemin mixture in the presence of the increasing concentration of compound 3. Differential spectra (Figure 6, left) were obtained by subtracting the spectra of the heme-compound mixture from the spectrum of the hemeantibody-compound mixture at the same concentration of the compound. It is clear that the compound has a strong effect on antibody-heme binding. However, due to the complexity of possible interactions in the tri-component mixture, it is difficult to deduce the nature of the observed effect. This is partially because the binding of $\mathrm{Ab} 21$ has a stronger effect on the hemin spectrum than the binding of the compound. The value of $\Delta A$ at the absorbance maximum of each differential spectrum was plotted against the concentration of compound 3 (Figure 6, right). It is possible that at the lower concentration of the compound, the dominant influence on the hemin spectrum is the blocking of the antibody-hemin binding (negative values of $\Delta A$ ). As the concentration of 3 approaches that of hemin, the spectral shift becomes the consequence of compoundhemin binding.

Induction of Ab21 Polyreactivity by Guanylhydrazones. Unexpectedly, two of the compounds studied for the inhibition of heme-mediated $\mathrm{Ab}$ polyreactivity were able to trigger antigen-binding polyreactivity of $\mathrm{Ab} 21$ themselves. The antibody was treated with a 30 -fold molar excess of tested compounds, and the binding of the native and treated antibody to three human antigens was evaluated by ELISA (Figure 7AC). Compounds 12 and 13 were inducing Ab21 binding to the studied antigens between 25 and $35 \%$ of the binding observed after exposure to heme. It is known that the $\mathrm{IgG}$ exposure to 

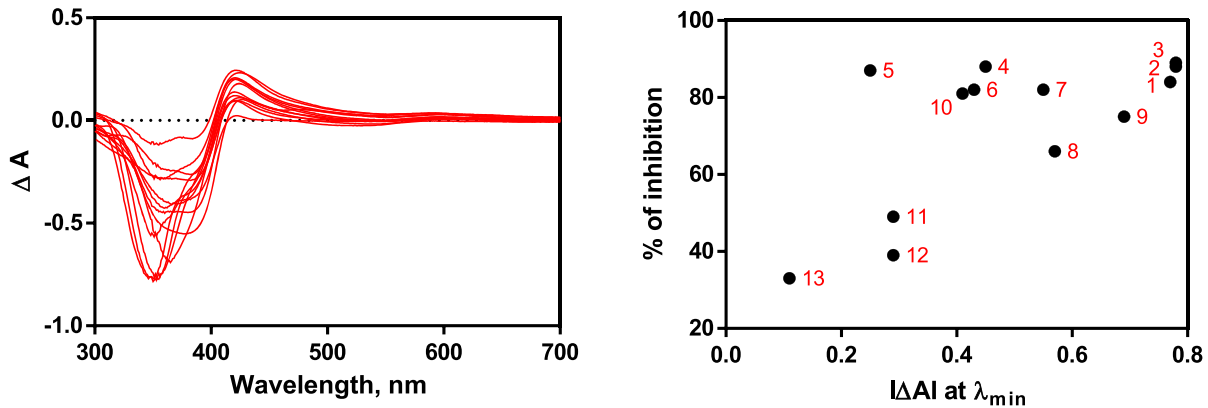

Figure 5. Left: the spectroscopic study of $20 \mu \mathrm{M}$ hemin with $100 \mu \mathrm{M}$ guanylhydrazones. Differential spectra were obtained by subtraction of the individual spectra of hemin and the compound from the spectrum of their mixture. Right: the percentage of the inhibition of heme-induced antibody binding to factor VIII plotted against the absolute value of $\Delta A$ at the absorbance minimum of each differential spectrum. Each dot represents one compound.
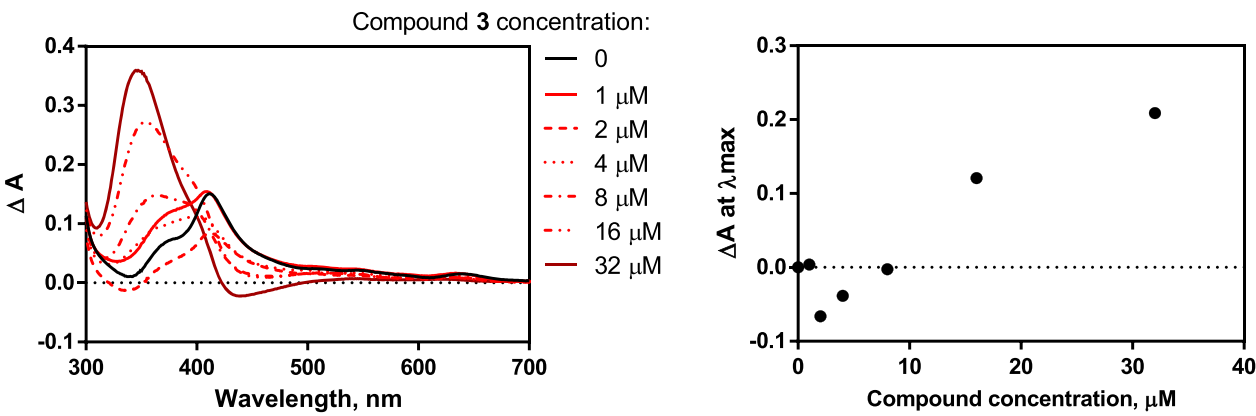

Figure 6. Left: the spectroscopic study of $16 \mu \mathrm{M}$ hemin and $2 \mu \mathrm{M} \mathrm{Ab} 21$, titrated with the increasing concentration $(0,1,2,4,8,16$, and $32 \mu \mathrm{M})$ of compound 3. Differential spectra were obtained by subtracting the spectra of the heme-compound mixture from the spectrum of the hemeantibody-compound mixture at the same concentration of the compound. Right: the value of $\Delta A$ at the absorbance maximum of each differential spectrum plotted against the concentration of compound 3 .

reactive oxygen species can also lead to the development of polyreactivity. ${ }^{10}$ When irradiated with visible light, protoporphyrin IX is known to produce these activated forms of oxygen. ${ }^{30}$ Indeed, we demonstrated that the ability of protoporphyrin IX to induce antibody binding to factor VIII increases when the experiment is repeated under ambient light. In contrast, the efficacy of compound 13 to influence $\mathrm{Ab}-$ protein binding did not depend on the presence of light (Figure 7D), which excludes the formation of ROS as its mechanism of action. Next, we wanted to investigate whether 13 gains polyreactivity-inducing ability because it forms a coordination complex with iron ions present in traces in the buffer solutions. To this end, Ab21 was exposed to increasing equimolar concentrations of compound 13 and an iron salt $\left(\mathrm{FeSO}_{4}\right.$ or $\left.\mathrm{FeCl}_{3}\right)$, independently and in the mixture, and the interaction with human factor VIII was elucidated by ELISA. The curve representing the sum of absorbance values obtained for compound $\mathbf{1 3}$ and iron alone was compared with that of the mixture (Figure 8). The addition of $\mathrm{Fe}$ (II) or $\mathrm{Fe}$ (III) ions did not significantly influence the polyreactivity-inducing potential of compound 13, indicating that the presence of iron ions is not needed for the effect. The results point to the conclusion that the induction of polyreactivity occurs by the direct interaction of a compound with the sensitive antibody, possibly by the same mechanism as that of heme.

Cytotoxicity Assessment of Compounds 3 and 4. Since these molecules are very efficient in preventing heme from binding to antibodies, they can serve as leads for the development of the new class of therapeutics to be used in the treatment of complications related to hemolytic diseases. Previous studies have demonstrated that this class of compounds is moderately toxic. ${ }^{25}$ Here, the antiproliferative activity of two most potent inhibitors was tested on human lung fibroblasts by the MTT assay. The concentration of the compound inhibiting cell growth by $50 \%\left(\mathrm{IC}_{50}\right)$ was $6.8 \mu \mathrm{M}$ for compound 3, and $8.4 \mu \mathrm{M}$ for compound 4 . Compared to $\mathrm{IC}_{50}$ of the widely used drug chloroquine $(58.0 \mu \mathrm{M})$, in the assay used, compounds were 8.5 and 6.9 times more toxic, suggesting that structural changes should be introduced to reduce the toxicity while keeping heme binding capacity, before the compounds can be considered for therapeutic use.

\section{CONCLUSIONS}

Previous data suggested that the necessary condition for hememediated antibody polyreactivity is the direct binding of heme to the antibody. To further test this premise, fourteen aromatic guanylhydrazones have been investigated for their ability to interact with heme and block the binding of the latter to the selected antibody (Ab21). Tested guanylhydrazones differ in the number of positively charged iminoguanidine groups and aromatic rings. Indeed, most of the studied molecules were able to inhibit the induction of antigen-binding polyreactivity to various extents. The inhibiting potential was shown to be decreasing with the increasing complexity of the molecules. Such result points to the conclusion that guanylhydrazones of less complex structures interact with heme by establishing $\pi$ stacking interactions; additional groups make it more difficult for the molecule to adopt planar conformation necessary for the efficient interaction. Other mechanisms for the more complex molecules can be considered. Steric hindrance in the proximity of iminoguanidine nitrogen atoms leads to the loss of the large part of the inhibiting potential, suggesting that the 

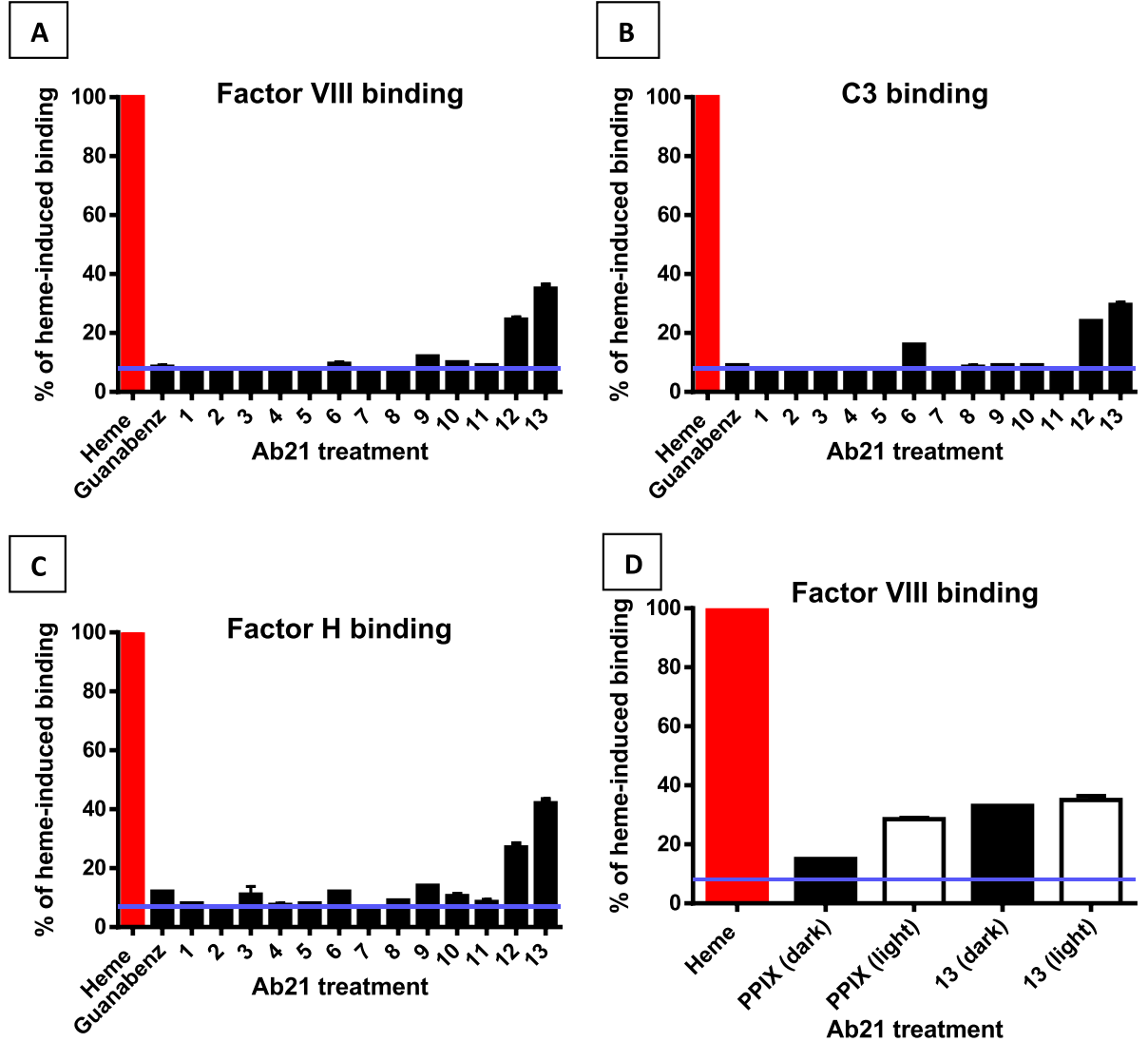

Figure 7. (A-C) Results of the study of induction of Ab21 polyreactivity by the immunosorbent assay. The binding to particular antigen was expressed as a percentage of the binding of the heme-exposed Ab21. (D) Induction of Ab21 polyreactivity by protoporphyrin IX and compound 13 with and without irradiation. Binding of native $\mathrm{Ab} 21$ is represented by the blue line.

nitrogen atom is involved in an important interaction with heme, possibly the coordination of the central metal ion. Investigation of the influence of guanylhydrazones on the absorbance spectra of heme demonstrated that there was a red shift of the absorbance maximum in the Soret region and significant lowering of the absorbance intensity. The extent of the change is in accordance with the hypothesis that strong coordinative interactions with iron are formed. The correlation between the spectral change and the inhibiting potential of the compounds implies that they inhibit heme-induced $\mathrm{Ab}$ polyreactivity by binding to heme, thus preventing the interaction with antibodies. It is noteworthy that the inhibitory capacity of most of the studied compounds was substantially higher than that of chloroquine. The interaction of heme with chloroquine is a well-elucidated archetypical case of molecular recognition of heme by a low molecular weight heterocyclic drug.

The surprising revelation was that two of the iminoguanidines were able to induce antibody polyreactivity without the presence of heme. We excluded the possibility that they generate reactive oxygen species under described experimental conditions or that the polyreactivity induction is assisted by iron ions present in solution. Thus, we concluded that they bind directly to the antibody and act as interfacial cofactors between the antibody and the antigen, similarly as heme does. Significantly lower inducing potential compared to heme highlights the importance of the unique heme structure and a possible contribution of coordination of heme's iron to the overall binding affinity to the antibody.
Additionally, the ability of guanylhydrazones to inhibit antibody polyreactivity induced by heme provides a possibility to control the biological effects of the release of large quantities of heme into circulation, related to hemolytic diseases. Previously found to be relatively nontoxic, these molecules can serve as leads for the development of a new class of therapeutics to be used in the treatment of hemolytic diseases and autoimmunity. Furthermore, the fact that they are more efficient in preventing heme from binding to antibodies than the well-known heme-inhibiting antimalarial agent chloroquine, suggests that their antimalarial activity should also be investigated.

\section{EXPERIMENTAL SECTION}

Hemin, $\mathrm{Fe}$ (III)-protoporphyrin IX chloride, was obtained from Frontier Scientific, Inc. (Logan, UT). Guanabenz, chloroquine diphosphate, DMSO, and protoporphyrin IX were obtained from Sigma-Aldrich (St. Louis, MO). All chemicals were with the highest available purity. The synthesis of compounds 1-13 was previously described. ${ }^{24-26}$ In brief, twelve aromatic aldehydes and one ketone were synthesized using the Suzuki-Miyaura reaction of an aryl halide and an appropriate boronic acid, and the final products were obtained by a onestep condensation reaction of aminoguanidine hydrochloride and the corresponding carbonyl compound. Details about the production of $\mathrm{Ab} 21$ are published elsewhere. ${ }^{31,32}$ Briefly, this is a human monoclonal IgG1 antibody whose variable genes encoding the immunoglobulin heavy and light chains were amplified from a B-cell by single-cell PCR from synovial tissue 
FVIII binding

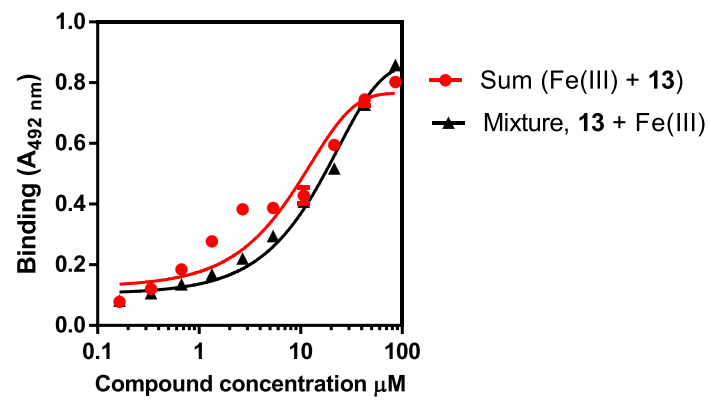

FVIII binding

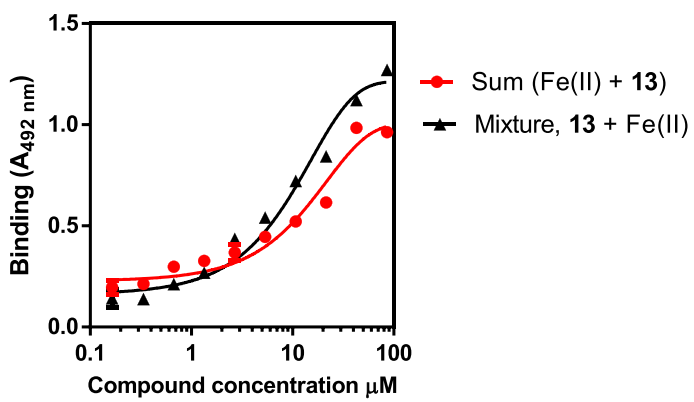

Figure 8. Effect of iron(III) and iron(II) ions on the induction of Ab21 polyreactivity by compound 13 . The sum of absorbance values for $\mathrm{Ab} 21$ treated with compound 13 and $\mathrm{Ab} 21$ treated with iron ions is shown in red circles. Black triangles represent absorbance values for $\mathrm{Ab} 21$ treated with increasing concentrations of an equimolar mixture of compound 13 and iron ions.

of rheumatoid arthritis patients, cloned in an expression vector containing the genes encoding the constant $\mathrm{Fc}-\gamma 1$ or $\kappa$ chain, respectively, and expressed using HEK293. Ab21 was thoroughly dialyzed against PBS containing $10 \%$ sucrose and stored before use at $-20{ }^{\circ} \mathrm{C}$ at a concentration of $12 \mathrm{mg} / \mathrm{mL}$. Human pooled immunoglobulin G (IVIg, Endobulin, Baxter) was dialyzed against $\mathrm{PBS}$ and stored before use at $-20{ }^{\circ} \mathrm{C}$ at a concentration of $80 \mathrm{mg} / \mathrm{mL}$. Hemin was dissolved in DMSO to a final concentration of $2 \mathrm{mM}$. Guanylhydrazones were dissolved in DMSO to a final concentration of $10 \mathrm{mM}$. The treatment of Ab21 was always performed with freshly prepared heme, at dim light conditions, unless stated otherwise. Measurements of heme-compound interactions were performed using following experimental setting: the UV-vis absorbance spectra were recorded by a Cary-300 spectrophotometer (Agilent Technologies, Santa-Clara, CA) using $1 \mathrm{~mL}$ quartz optical cells (Hellma, Jena, Germany) with a $1 \mathrm{~cm}$ optical path. The spectra were recorded in the wavelength range of 300-700 nm with a spectral resolution of $1 \mathrm{~nm}$ and a bandwidth set at $2 \mathrm{~nm}$. The absorbance background derived by the buffer was only subtracted from each reading. Measurements were performed at room temperature.

Immunosorbent Assay for Heme-Induced Ab21 Polyreactivity. Ninety-six-well polystyrene plates (Nunc MaxiSorp) were coated with human factor VIII, human C3, and human factor $\mathrm{H}$ and diluted to $2 \mu \mathrm{g} / \mathrm{mL}$ in PBS. After incubation for $2 \mathrm{~h}$ at room temperature, the residual binding sites on plates were blocked by PBS containing $0.25 \%$ Tween 20. For treatment, $\mathrm{Ab} 21$ was diluted to $500 \mu \mathrm{g} / \mathrm{mL}(3.33 \mu \mathrm{M})$ and exposed to $6.67 \mu \mathrm{M}$ final concentration of hemin. After 10 min of incubation on ice, native and heme-exposed Ab21 was first diluted with PBS-T (0.05\% Tween 20$)$ to $100 \mu \mathrm{g} / \mathrm{mL}$. It was further serially diluted with PBS-T in the range of 0.097$100 \mu \mathrm{g} / \mathrm{mL}$ (dilution factor of 2) and incubated for $1 \mathrm{~h}$ at room temperature with plates coated with the studied proteins. After incubation with antibodies, plates were washed extensively with PBS-T and incubated with a peroxidaseconjugated mouse anti-human IgG (clone JDC-10, Southern Biotech, Birmingham, $\mathrm{AL}$ ) for $1 \mathrm{~h}$ at room temperature. Immunoreactivity of $\mathrm{Ab} 21$ was revealed by measuring the absorbance at $492 \mathrm{~nm}$ after the addition of peroxidase substrate, $o$-phenylenediamine dihydrochloride (Sigma-Aldrich) and stopping the reaction by the addition of $2 \mathrm{M}$ $\mathrm{HCl}$. Measurement of the absorbance was performed with a microplate reader (Infinite 200 Pro, Tecan).

Following sections describe variations of the procedure. Initial and final steps of the experiments are identical to those described above.

Immunosorbent Assay for the Study of Inhibition of Heme-Induced Ab21 Polyreactivity. Ab21 was diluted to 100 $\mu \mathrm{g} / \mathrm{mL}$ and exposed to $20 \mu \mathrm{M}$ final concentration of tested compounds. After $10 \mathrm{~min}$ of incubation on ice, compoundtreated $\mathrm{Ab} 21$ was exposed to $10 \mu \mathrm{M}$ of hemin. As a positive control, Ab21 at $100 \mu \mathrm{g} / \mathrm{mL}$ was treated only with $10 \mu \mathrm{M}$ of hemin. After $15 \mathrm{~min}$ of incubation on ice, native and compound and/or heme-exposed Ab21 was first diluted with PBS-T (0.05\% Tween 20) to a final concentration of $10 \mu \mathrm{g} /$ $\mathrm{mL}$ and incubated for $1 \mathrm{~h}$ at room temperature with plates coated with the studied proteins.

Comparison of Inhibitory Potential of Compounds 3 and 4 by Immunosorbent Assay. Ab21 was diluted to $100 \mu \mathrm{g} / \mathrm{mL}$ $(0.67 \mu \mathrm{M})$ and IVIg was diluted to $1 \mathrm{mg} / \mathrm{mL}(6.67 \mu \mathrm{M})$. Antibody solutions were exposed to decreasing concentrations (85.76, 42.88, 21.44, 10.72, 5.36, 2.68, 1.34, 0.67, 0.33, and 0 $\mu \mathrm{M})$ of compound 3 or 4 . After $10 \mathrm{~min}$ of incubation on ice, compound-treated antibodies were exposed to $10 \mu \mathrm{M}$ of hemin. After $15 \mathrm{~min}$ of incubation on ice, native and compound and/or heme-exposed antibodies were first diluted with PBS-T (0.05\% Tween 20) to the final concentrations of $10 \mu \mathrm{g} / \mathrm{mL}$ for $\mathrm{Ab} 21$ and $100 \mu \mathrm{g} / \mathrm{mL}$ for IVIg, and incubated for $1 \mathrm{~h}$ at room temperature with a plate coated with the studied proteins.

Immunosorbent Assay for the Study of Induction of Ab21 Polyreactivity. Ab21 was diluted to $100 \mu \mathrm{g} / \mathrm{mL}$ and exposed to $20 \mu \mathrm{M}$ final concentration of tested compounds. As a positive control, $\mathrm{Ab} 21$ at $100 \mu \mathrm{g} / \mathrm{mL}$ was treated with $10 \mu \mathrm{M}$ of hemin. After $10 \mathrm{~min}$ of incubation on ice, native and compound exposed Ab21 was first diluted with PBS-T (0.05\% Tween 20) to a final concentration of $10 \mu \mathrm{g} / \mathrm{mL}$ and incubated for $1 \mathrm{~h}$ at room temperature with plates coated with the studied proteins.

Immunosorbent Assay for the Study of the Effect of Iron Ions on the Induction of Ab21 Polyreactivity by Compound 13. Ab21 was diluted to $100 \mu \mathrm{g} / \mathrm{mL}(0.67 \mu \mathrm{M})$ and exposed to decreasing concentrations $(85.76,42.88,21.44,10.72,5.36$, $2.68,1.34,0.67,0.33$, and $0 \mu \mathrm{M})$ of compound 13 , iron salt $\left(\mathrm{FeCl}_{3}\right.$ or $\left.\mathrm{FeSO}_{4}\right)$, or the mixture of compound and iron. After $15 \mathrm{~min}$ of incubation on ice, native and compound and/or iron-exposed Ab21 was first diluted with PBS-T (0.05\% Tween 20) to a final concentration of $10 \mu \mathrm{g} / \mathrm{mL}$ and incubated for $1 \mathrm{~h}$ at room temperature with the plate coated with the studied proteins.

Comparison of Inhibitory Potential of Compounds 3 and 4 by Western Blot. Bacterial antigens from B. anthracis cell lysate were first separated by SDS-PAGE (Novex NuPAGE 
4-12\% Bis-Tris gel, $1.0 \mathrm{~mm}$, Life Technologies) and then transferred onto nitrocellulose membranes using an iBlot dry transfer system (Life Technologies). After incubation at $4{ }^{\circ} \mathrm{C}$ overnight with PBS-Tween $0.1 \%$, membranes were mounted in the Miniblot apparatus (Immunetics, Boston, MA). Ab21 was treated at a $100 \mu \mathrm{g} / \mathrm{mL}$ concentration in PBS, with hemin solubilized in DMSO (final heme concentration $2.5 \mu \mathrm{M}$ ) and with decreasing concentrations of guanylhydrazones (100, 50, $25,12.5,6.25,3.12,1.56,0.78,0.39$, and $0 \mu \mathrm{M})$. After $15 \mathrm{~min}$ of incubation, native and treated Ab21 was diluted 10-fold in PBS-Tween $0.1 \%$ and loaded on Miniblot channels. After $1 \mathrm{~h}$ of incubation at room temperature, nitrocellulose membranes were removed from the Miniblot apparatus, washed for $1 \mathrm{~h}$ with PBS-Tween $0.1 \%$ and incubated with alkaline phosphatase-conjugated goat anti-human IgG antibody (Southern Biotech). The enzymatic reaction was performed using the BCIP/NBT substrate (Sigma-Aldrich).

Spectroscopic Analyses of Interaction of Heme with Guanylhydrazone Compounds. Hemin was diluted to 20 $\mu \mathrm{M}$ in PBS. The UV-vis spectra in the absence and presence of $100 \mu \mathrm{M}$ final concentration of compounds were recorded. The UV-vis spectra of $100 \mu \mathrm{M}$ final concentration of compounds in PBS were recorded. Differential spectra were obtained after subtraction of spectra of heme and compound alone from the spectrum the heme-compound mixture.

Spectroscopic Analyses of the Influence of Guanylhydrazone Compound 3 on Antibody-Heme Interactions. A mixture of Ab21 $(2 \mu \mathrm{M})$ and hemin $(16 \mu \mathrm{M})$ in PBS was titrated with the increasing concentrations of compound 3 $(0,1,2,4,8,16$, and $32 \mu \mathrm{M})$. Hemin alone at $16 \mu \mathrm{M}$ in PBS was titrated with the same concentrations of compound 3 . Differential spectra were obtained after subtraction of spectra of heme and compound from the spectra of the hemeantibody-compound mixture at the same concentration of the compound.

Antiproliferative Activity of Chloroquine and Compounds 3 and 4. Antiproliferative activity of the compounds was tested on human lung fibroblasts (MRC5; ATCC collection) by 3-(4,5-dimethylthiazol-2-yl)-2,5-diphenyltetrazolium bromide (MTT) assay. The cells were incubated in the media containing test compounds at concentrations ranging from 0.1 to $250 \mu \mathrm{g} / \mathrm{mL}$ and the cell viability was measured after 48 h. The MRC5 cell line was cultured in RPMI-1640 medium supplemented with $100 \mu \mathrm{g} / \mathrm{mL}$ streptomycin, $100 \mathrm{U} /$ $\mathrm{mL}$ penicillin and $10 \%(\mathrm{v} / \mathrm{v})$ fetal bovine serum (FBS) (all from Sigma, Munich, Germany). The cells were maintained as a monolayer $\left(1 \times 10^{4}\right.$ cells per well $)$ in RPMI-1640 and grown in a humidified atmosphere of $95 \%$ air and $5 \% \mathrm{CO}_{2}$ at $37{ }^{\circ} \mathrm{C}$. The extent of MTT reduction was determined by measuring the absorbance at $540 \mathrm{~nm}$ with a microplate reader (Infinite 200 Pro, Tecan) and the cell survival was expressed as a percentage of the control (untreated cells). Cytotoxicity is expressed as the concentration of the compound inhibiting growth by $50 \%\left(\mathrm{IC}_{50}\right)$.

\section{ASSOCIATED CONTENT}

\section{S Supporting Information}

The Supporting Information is available free of charge at https://pubs.acs.org/doi/10.1021/acsomega.9b01548.

Differential spectra for compounds 1-13 obtained by subtraction of the individual spectra of hemin and the compound from the spectrum of their mixture (PDF)

\section{AUTHOR INFORMATION}

\section{Corresponding Authors}

*E-mail: nina.bozinovic@inserm.fr. Tel: +33 144278201 . Fax: +33144278194 (N.B.).

*E-mail: jordan.dimitrov@crc.jussieu.fr, jordan.dimitrov@ inserm.fr. Tel: +331 442782 06. Fax: +331 44278194 (J.D.D.).

ORCID

Nina Božinović: 0000-0002-6476-2202

Vladimir Ajdačić: 0000-0002-3423-0862

Igor M. Opsenica: 0000-0003-4942-4042

Notes

The authors declare no competing financial interest.

\section{ACKNOWLEDGMENTS}

This work was supported by the European Research Council (grant ERC-StG-678905 CoBABATI to J.D.D.), the INSERM, the Ministry of Education, Science and Technological Development of Serbia (Grant No. 172008), and the PHC French-Serbian partnership project Pavle Savić (451-0301963/2017-09/03).

\section{REFERENCES}

(1) Saada, R.; Weinberger, M.; Shahaf, G.; Mehr, R. Models for antigen receptor gene rearrangement: CDR3 length. Immunol. Cell Biol. 2007, 85, 323-332.

(2) Collins, A. M.; Jackson, K. J. L. On being the right size: antibody repertoire formation in the mouse and human. Immunogenetics 2018, $70,143-158$

(3) Van Regenmortel, M. H. From absolute to exquisite specificity. Reflections on the fuzzy nature of species, specificity and antigenic sites. J. Immunol. Methods 1998, 216, 37-48.

(4) Notkins, A. L. Polyreactivity of antibody molecules. Trends Immunol. 2004, 25, 174-179.

(5) Dimitrov, J. D.; Planchais, C.; Roumenina, L. T.; Vassilev, T. L.; Kaveri, S. V.; Lacroix-Desmazes, S. Antibody polyreactivity in health and disease: statu variabilis. J. Immunol. 2013, 191, 993-999.

(6) Van Regenmortel, M. H. Specificity, polyspecificity, and heterospecificity of antibody-antigen recognition. J. Mol. Recognit. 2014, 27, 627-639.

(7) Gunti, S.; Messer, R. J.; Xu, C.; Yan, M.; Coleman, W. G., Jr.; Peterson, K. E.; Hasenkrug, K. J.; Notkins, A. L. Stimulation of tolllike receptors profoundly influences the titer of polyreactive antibodies in the circulation. Sci. Rep. 2015, 5, No. 15066.

(8) McIntyre, J. A. The appearance and disappearance of antiphospholipid autoantibodies subsequent to oxidation-reduction reactions. Thromb. Res. 2004, 114, 579-587.

(9) McIntyre, J. A.; Wagenknecht, D. R.; Faulk, W. P. Autoantibodies unmasked by redox reactions. J. Autoimmun. 2005, 24, 311317.

(10) Dimitrov, J. D.; Ivanovska, N. D.; Lacroix-Desmazes, S.; Doltchinkova, V. R.; Kaveri, S. V.; Vassilev, T. L. Ferrous ions and reactive oxygen species increase antigen-binding and anti-inflammatory activities of immunoglobulin G. J. Biol. Chem. 2006, 281, 439446.

(11) Dimitrov, J. D.; Roumenina, L. T.; Doltchinkova, V. R.; Mihaylova, N. M.; Lacroix-Desmazes, S.; Kaveri, S. V.; Vassilev, T. L. Antibodies use heme as a cofactor to extend their pathogen elimination activity and to acquire new effector functions. J. Biol. Chem. 2007, 282, 26696-26706.

(12) Mihaylova, N. M.; Dimitrov, J. D.; Djoumerska-Alexieva, I. K.; Vassilev, T. L. Inflammation-induced enhancement of IgG immunoreactivity. Inflammation Res. 2008, 57, 1-3.

(13) Hadzhieva, M.; Vassilev, T. L.; Roumenina, L. T.; Bayry, J.; Kaveri, S. V.; Lacroix-Desmazes, S.; Dimitrov, J. D. Mechanism and 
functional implications of the heme-induced binding promiscuity of IgE. Biochemistry 2015, 54, 2061-2072.

(14) Dimitrov, J. D.; Planchais, C.; Scheel, T.; Ohayon, D.; Mesnage, S.; Berek, C.; Kaveri, S. V.; Lacroix-Desmazes, S. A cryptic polyreactive antibody recognizes distinct clades of HIV-1 glycoprotein 120 by an identical binding mechanism. J. Biol. Chem. 2014, 289, 17767-17779.

(15) Kühl, T.; Imhof, D. Regulatory $\mathrm{Fe}(\mathrm{II} / \mathrm{III})$ heme: the reconstruction of a molecule's biography. ChemBioChem 2014, 15, 2024-2035.

(16) Lecerf, M.; Scheel, T.; Pashov, A. D.; Jarossay, A.; Ohayon, D.; Planchais, C.; Mesnage, S.; Berek, C.; Kaveri, S. V.; Lacroix-Desmazes, S.; Dimitrov, J. D. Prevalence and gene characteristics of antibodies with cofactor-induced HIV-1 specificity. J. Biol. Chem. 2015, 290, 5203-5213.

(17) Gupta, N.; de Wispelaere, M.; Lecerf, M.; Kalia, M.; Scheel, T.; Vrati, S.; Berek, C.; Kaveri, S. V.; Desprès, P.; Lacroix-Desmazes, S.; Dimitrov, J. D. Neutralization of Japanese Encephalitis Virus by hemeinduced broadly reactive human monoclonal antibody. Sci. Rep. 2015, 5, No. 16248.

(18) Li, Z.; Khaliq, M.; Zhou, Z.; Post, C. B.; Kuhn, R. J.; Cushman, M. Design, Synthesis, and Biological Evaluation of Antiviral Agents Targeting Flavivirus Envelope Proteins. J. Med. Chem. 2008, 51, 4660-4671.

(19) Mayhoub, A. S.; Khaliq, M.; Botting, C.; Li, Z.; Kuhn, R. J.; Cushman, M. An investigation of phenylthiazole antiflaviviral agents. Bioorg. Med. Chem. 2011, 19, 3845-3854.

(20) Merlino, A.; Benitez, D.; Chavez, S.; Da Cunha, J.; Hernández, P.; Tinoco, L. W.; Campillo, N. E.; Páez, J. A.; Cerecetto, H.; González, M. Development of second generation amidinohydrazones, thio- and semicarbazones as Trypanosoma cruzi-inhibitors bearing benzofuroxan and benzimidazole 1,3-dioxide core scaffolds. Med. Chem. Commun. 2010, 1, 216-228.

(21) Mohammad, H.; Younis, W.; Chen, L.; Peters, C. E.; Pogliano, J.; Pogliano, K.; Cooper, B.; Zhang, J.; Mayhoub, A.; Oldfield, E.; Cushman, M.; Seleem, M. N. Phenylthiazole Antibacterial Agents Targeting Cell Wall Synthesis Exhibit Potent Activity in Vitro and in Vivo against Vancomycin-Resistant Enterococci. J. Med. Chem. 2017, 60, 2425-2438.

(22) Eissa, I. H.; Mohammad, H.; Qassem, O. A.; Younis, W.; Abdelghany, T. M.; Elshafeey, A.; Abd Rabo Moustafa, M. M.; Seleem, M. N.; Mayhoub, A. S. Diphenylurea derivatives for combating methicillin- and vancomycin-resistant Staphylococcus aureus. Eur. J. Med. Chem. 2017, 130, 73-85.

(23) Heinzl, G. A.; Huang, W.; Yu, W.; Giardina, B. J.; Zhou, Y.; MacKerell, A. D., Jr.; Wilks, A.; Xue, F. Iminoguanidines as Allosteric Inhibitors of the Iron-Regulated Heme Oxygenase (HemO) of Pseudomonas aeruginosa. J. Med. Chem. 2016, 59, 6929-6942.

(24) Lazić, J.; Ajdačić, V.; Vojnovic, S.; Zlatović, M.; Pekmezovic, M.; Mogavero, S.; Opsenica, I.; Nikodinovic-Runic, J. Bis-guanylhydrazones as efficient anti-Candida compounds through DNA interaction. Appl. Microbiol. Biotechnol. 2018, 102, 1889-1901.

(25) Ajdačić, V.; Senerovic, L.; Vranic, M.; Pekmezovic, M.; ArsicArsnijevic, V.; Veselinovic, A.; Veselinovic, J.; Šolaja, B. A.; Nikodinovic-Runic, J.; Opsenica, I. M. Synthesis and evaluation of thiophene-based guanylhydrazones(iminoguanidines) efficient against panel of voriconazole-resistantfungal isolates. Bioorg. Med. Chem. 2016, 24, 1277-1291.

(26) Ajdačić, V.; Lazić, J.; Mojićević, M.; Šegan, S.; NikodinovicRunic, J.; Opsenica, I. M. Antibacterial and antifungal properties of guanylhydrazones. J. Serb. Chem. Soc. 2017, 82, 641-649.

(27) Olafson, K. N.; Nguyen, T. Q.; Rimer, J. D.; Vekilov, P. G. Antimalarials inhibit hematin crystallization by unique drug-surface site interactions. Proc. Natl. Acad. Sci. U.S.A. 2017, 114, 7531-7536.

(28) Walker, B. R.; Hare, L. E.; Deitch, M. W. Comparative antihypertensive effects of guanabenz and clonidine. J. Int. Med. Res. 1982, 10, 6-14.

(29) Egan, T. J. Interactions of quinoline antimalarials with hematin in solution. J. Inorg. Biochem. 2006, 100, 916-926.
(30) Sachar, M.; Anderson, K. E.; Ma, X. Protoporphyrin IX: the Good, the Bad, and the Ugly. J. Pharmacol. Exp. Ther. 2016, 356, $267-275$.

(31) Scheel, T.; Gursche, A.; Zacher, J.; Haupl, T.; Berek, C. Vregion gene analysis of locally defined synovial $\mathrm{B}$ and plasma cells reveals selected B cell expansion and accumulation of plasma cell clones in rheumatoid arthritis. Arthritis Rheum. 2011, 63, 63-72.

(32) Scheel, T. Die B-Zell-Antwort im Synovialgewebe von Patienten mit Rheumatoider Arthritis. Doctoral Thesis, HumboldtUniversität zu Berlin, 2009. 